\title{
THE RISK PLANNING METHODOLOGICAL PRINCIPLES FOR HOUSING INVESTMENT
}

\author{
Olena Balanska', Olexandr Yemelyanov ${ }^{2}$
}

\begin{abstract}
In many countries wordwide there is an urgent need to increase the housing level. However, a significant increase in this level is hindered by a number of factors. Among these factors, the significant risk of housing construction investing is essential. Reducing the riskiness of housing construction investing requires, among other things, the use of scientifically grounded risk planning methods in such investment. With taking this into account, the purpose of this work is to develop methodological principles for the housing investing risk planning. The study subjects were the patterns of forming the housing construction investing risks. The methodology of this study involved the use of systems analysis, economic and mathematical modeling, tools of decision theory, and technical and economic calculations. Among the results of the study, the formed input information array needed for planning the housing investing risks should be noted. This array includes the following main blocks: information on the available regulatory and legal support for housing construction; information on potential developers, intermediaries, and other entities investing in housing construction (particularly on the occurrence of risky events' frequency and scale in their activities); information on potential investment objects (such as their preliminary estimated costs, consumer characteristics, construction terms); information on the concluding agreements' conditions and procedure between the housing construction investment subjects. The indicator system for retrospective assessment in housing construction investing risk is proposed. In particular, the following indicators groups are included in this system: actual frequency indicators of risky events' occurrence in the investment entities' activity in the previous period(s); specific indicators of the risky events' occurrence scale in the investment entities' activities in the previous period(s); relative indicators of the risky events' occurrence scale in the investment entities' activities in the previous period(s). Also, this indicators system was supplemented by a number of generalizing indicators. The sequence of the risk planning process in housing construction investing for all the main participants of the process is proposed. For the investors particularly, this sequence contains the following sequential actions: a set of situations in which the construction object may appear is formed; the probability for each of these situations is estimated; the expected value of the economic benefit from the housing purchase in each situation is set; the mathematical expectation calculation of the value of economic benefits from the housing purchasing is made; the coefficient of variation is calculated according to the average linear deviation of economic benefits from the housing purchasing; the estimated market value of a residential real estate object is calculated taking into account the risk factor; the profitability index of the particular dwelling purchase operation is calculated. The practical implication of the developed methodological principles of the risk planning in housing construction investing in the practice of the construction subjects will increase the approved management decisions validity.
\end{abstract}

Key words: investment project, investor, developer, evaluation, risk, indicator.

JEL Classification: D81, G31, L74

\section{Introduction}

One of the leading indicators of living standards is housing availability. Achieving a high level of this indicator requires adequate volumes of housing construction. However, certain factors hinder its development. In particular, these factors include the housing construction investing risk.

In general, housing purchasing should be considered a specific investment project. In turn, modern management science and practice offer

\footnotetext{
Corresponding author:

${ }^{1}$ Lviv Polytechnic National University, Ukraine.

E-mail: olena.i.balanska@lpnu.ua

ORCID: https://orcid.org/0000-0003-4849-0080

${ }^{2}$ Lviv Polytechnic National University, Ukraine.

E-mail: oleksandr.y.yemelianov@lpnu.ua

ORCID: https://orcid.org/0000-0002-1743-1646
} 
effective tools for project analysis and management (Flyvbjerg, 2006; Serra et al., 2014). The use of such tools makes it possible to increase the success of investment projects (Chan et al., 2004; Shenhar et al., 2001). This is achieved, mainly, by concidering all the main factors of such success and formalizing the projects' characteristics evaluating process (Cho et al., 2005).

One of the most critical characteristics of projects is their riskiness, which is the threat of partial or total failure of obtaining the expected results from the project's implementation. Taking into account the project's risk level requires the use of unique indicators and methods (Jaafari, 2001; Lesinskyi et al., 2018; Renn et al., 2013; Yemelyanov et al., 2018). The projects specific (Ho et al., 1992), particularly housing investment projects, should be taken into account. The riskiness of such investment is due to a number of factors, such as its significant duration, the complexity of the relationship between the participants in the investment process (Doloi, 2009).

The housing investment risk factor has been examined in a several of scientific papers ( $\mathrm{Abu}$ Hassan et al., 2012; Akintoye et al., 1997; Baloi et al., 2003; Berk et al., 2012; Lian et al., 2017). However, methodological bases developing for such a risk planning are not definitively resolved and require further research. First of all, it is necessary to examine the peculiarities of such planning for all major participants in the housing construction investment process, particularly for investors, developers, intermediaries, and others.

\section{The essence and information support of the risks planning process in housing construction investing}

Under the investing risks planning in housing construction, it is advisable to understand the investment process subjects' actions to establish a reasonable level of their activities' riskiness in this process. It is necessary to establish planning criteria and determine the parameters, the optimal or normative values of which should be chosen by the planning entity, to carry out such planning. In particular, the norms include most of the construction process indicators (such as duration, the investment distribution during the construction period, the production resources spendings). Regarding the risk planning parameters for housing construction investment, which are a subject for optimization, they include those that should a priori be chosen from several alternatives. In particular, we can talk about the choice of a certain developer and intermediary, the best investment scheme, and others. Thus, the risk planning methodology of residential construction projects should include a combination of regulatory and optimization methods of such planning. This combination can also be reflected in the fact that the obtained investment process's optimal parameters may be specific standards for other entities that find themselves in similar conditions.

Planning the housing investing risks requires the prior forming of a wide array of input information. It is advisable to highlight the following main blocks of this information:

1) information on the available regulatory and legal support for housing construction;

2 ) information on potential developers, intermediaries, and other entities investing in housing construction (in particular, on the occurrence frequency and scale of risky events in their activities);

3) information on potential investment objects (such as their preliminary estimated cost, consumer characteristics, construction terms);

4) information on the agreements concluding conditions and procedure between the subjects of housing construction investment.

\section{The retrospective assessment indicators of housing construction investing risk}

While assessing the risk events frequency and scale in the housing investing entities activities, it is necessary to identify the following indicators groups for assessing the relevant investment risk characteristics:

1) indicators of the actual risk events frequency in the investment entities' activities in the previous period(s). It has to be chosen the basis on which such a frequency will be computed, to calculate these indicators. In particular, such a base for the developer may be the total square meters number of housing built, and for investors and intermediaries - the total square meters number of housing purchased by them in the previous period (s);

2) specific indicators of the risky events occurrence scale in the investment entities' activities in the previous period (s). The average amount of losses incurred by investment entities per unit of the selected base should be computed to calculate these indicators. In particular, specific indicators can be measured in monetary units per square meter of commissioned housing. In this case, the indicators can be computed both in the calculation of the entire database volume and in the calculation of the part of this database in respect of which risky events have occurred;

3) relative indicators of the risky events' occurrence in the investment entities' activities in the previous period (s). It is necessary to compare the number of losses incurred by investment entities with certain cost characteristics of the commissioned residential premises, particularly with their estimated cost, to calculate these indicators. As in the case of specific indicators, relative indicators can be calculated both 
on the total estimated value basis of the commissioned dwellings and on the part of this value basis that corresponds to the base regarding which the risk events occurred.

It is advisable to identify three main risk events: unpredictable increase in construction costs; the consumer properties of residential premises deterioration compared to the predetermined level of these properties; delay in the residential premises commissioning. If we consider the losses from these risky events occurrences from the investors' point of view (if there are no unique mechanisms to compensate these losses, which were laid down in the text of the agreements between housing investing entities), the amount of these losses is determined as follows:

1 ) in case of an unforeseen increase in the construction cost, the losses amount is determined by the magnitude of such growth;

2 ) in case of the consumer properties of residential premises deterioration in comparison with the predetermined level of these properties, the losses amount is determined by the amount of housing market value reduction in comparison with the situation when such deterioration of housing consumer properties did not happen (or by the additional investor expenses to eliminate consequences);

3 ) in the event of a delay in the residential premises commissioning, the investor's loss amount may be estimated by the amount of rent that he would have received by giving the premises for rent for the period of this delay.
Thus, it is possible to offer the indicators system for retrospective risk assessment of housing construction investing. This system contains indicators that allow us to assess the extent and economic consequences of each of the significant risk events for investors, developers, and intermediaries (Figure 1).

In practice, in the case of a direct relationship between the investor and the developer, the central part of the investment risks (especially the risk of residential facility's untimely commissioning) is borne by the investor. Therefore, the most interesting cases are indicators of the risk events' actual frequency for developers and indicators of the events occurrence scale for investors who have dealt with specific developers.

It also seems appropriate to supplement the above indicators system for retrospective risk assessment in housing construction investing with generalizing indicators. These indicators can be the following:

- their actual occurrence frequency in the developer's activities, the standard for all-risk events. This frequency can be measured by the share of living space meters total number put into operation in the reporting period (s) for which at least one risk event occurred;

- the total specific scale of all risk events occurs in investors' activities who had a relationship with the certain developer. The amount of investor losses received from all possible risk events is first calculated to compute this indicator. Then this value is divided by the total number of living space meters put into operation in the reporting period(s), for which there was at least one risky event;

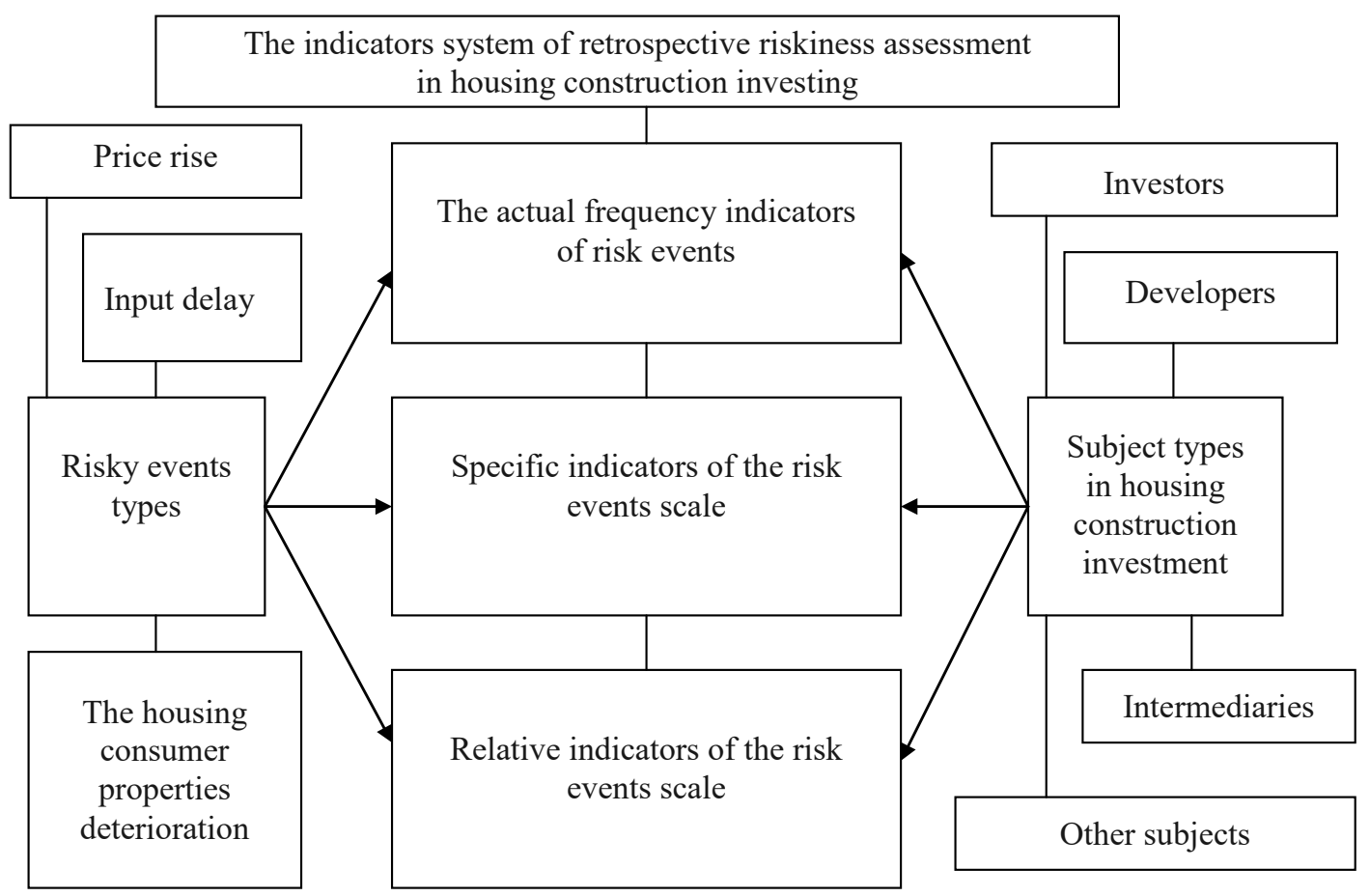

Figure 1. The indicators system of retrospective riskiness assessment in housing construction investing Source: developed by the authors 
- the overall relative scale of all risk events in that investors' activities who had a relationship with the developer. The investor losses number is first calculated to compute this indicator, as in the previous case. This value is then divided by the initial estimated cost of the living space total meters number put into operation in the reporting period(s) for which at least one risk event occurred.

These three summary indicators can be used to process the developers' attractiveness assessment for potential investors.

\section{The sequence of the risks planning process in the housing investing}

When considering the risk planning process in housing investing, it should be taken into account that this process will differ for all investment subjects. In particular, concerning the investors, when planning their risks, the function of probabilities distributing the expected economic benefit from the residential real estate purchase should be built first of all. In order to implement such a construction and other risk planning process, the following sequence of actions should be performed:

1) the situations set is formed in which the construction object may appear;

2) for each of these situations, its probability is estimated;

3) the expected economic benefit value from the housing purchase in each situation is set. This value can be calculated as the difference between the capitalization of net rent for the relevant premises and the expected investor's losses number in case of this situation:

$$
E_{i}=\frac{P}{r}-L_{i},
$$

where:

$E_{i}$ is the value of economic benefits from the housing purchase in the $i$-th situation, monetary units;

$P$ is the annual value of net rent, monetary units;

$r$ is the annual risk-free capitalization rate in the $i$-th situation, unit share;

$L_{i}$ is the expected investor's losses value due to the occurrence of a risky event(s) in the $i$-th situation, monetary units;

4) the mathematical expectation calculation of the value of economic benefits from the housing purchase is performed:

$$
M=\sum_{i=1}^{n}\left(E_{i} \cdot P_{r i}\right) \text {, }
$$

where:

$M$ is the mathematical expectation of the value of economic benefits from the housing purchasing, monetary units;

$n$ is the number of possible situations in which a residential property may find itself;
$P_{r i}$ is the probability of the $i$-th situation occurrence;

5 ) the coefficient of variation calculation on the average linear deviation of economic benefits from the housing purchasing is performed:

$$
c_{v}=\frac{\sum_{i=1}^{n}\left(\left|E_{i}-M\right| \cdot I_{i}\right)}{M},
$$

where:

$c_{v}$ is the coefficient of variation on the average linear deviation of economic benefits from the housing purchasing, unit share;

6) the estimated market value of the residential real estate object is calculated by taking the risk factor into account:

$$
V=M \cdot\left(1-\frac{c_{v}}{c_{v m}}\right),
$$

where:

$V$ is the estimated market value of residential real estate with taking the risk factor into account, monetary units;

$\mathcal{c}_{v m}$ is the maximum possible value of the coefficient of variation on the average linear deviation (for positive values of the random variable is 2 ), unit share;

7) the profitability index for the certain housing purchasing transaction is calculated:

$$
I=V / V_{0},
$$

where:

I is the profitability index for the particular housing purchasing transaction, times;

$V_{0}$ is the initial estimated cost of this building, monetary units.

If the profitability index calculated according to formula (5) exceeds one, then the housing purchasing should be considered appropriate. If the value of the profitability index is less than one, then buying such housing is impractical.

Regarding the risk value planning for the intermediary involved in the housing construction investing process, such planning is generally similar to the sequence of this process described above for the investor. However, additionally the following circumstances should be taken into account: 1) the intermediary's economic benefits are determined by the belonging to him share of housing buyer investment costs; 2) the intermediary's riskiness depends on what investment risks are transferred to him and whether they are insured; 3) while planning the intermediary's risks instead of the premises' initial estimated cost the assets amount involved in the intermediary's activities should be taken.

The proposed approach to the investor's (the housing buyer) risk planning under certain modifications can be extended to the case of the enterprise - the developer. However, the distributing function probability of a developer's profit from the housing construction and sale can be a function of many variables (for example, each situation may correspond 
to a certain amount of developer's expenses not covered by the investor and a certain amount of unsold housing in square meters). Also, when planning the risks of the enterprise - the developer, the issue of determining the minimum allowable for such an enterprise initial estimated cost of each dwelling (or square meter of its area) is resolving. It is proposed to perform the following sequence of actions to solve this problem: 1) the probabilities distribution function of the developer's expected profit from the particular dwelling construction and sale at a certain estimated cost of this room is built; 2) the mathematical expectation and the coefficient of variation of this profit at a certain estimated housing cost is calculated; 3 ) the capitalized profit amount is determined using the risk-free capitalization rate; 4) the value of the developer's assets involved in the particular dwelling construction and sale is determined taking into account the premises area fraction in the total housing area that is put into operation by the developer and its construction and marketing processes duration; 5) the relationship between the housing construction estimated cost and the capitalized developer's profit amount, obtained as a result of housing construction and sale is built; 6) such housing estimated value, at which the developer's profit capitalized value from the housing construction and sale becomes equal to the developer's assets value calculated at the fourth stage, is determined. This cost will be the minimum allowable for the developer's estimated construction cost of a particular dwelling.

The authors analyzed the housing construction activities of a number of construction companies in the western region of Ukraine. The planned indicators of the housing construction investing risk for these developers on a sample of residential premises, the construction of which was expected to begin in 2019 were calculated (Table 1).

According to the data in Table 1, for most of the dwellings planned to be constructed, the profitability index (5) ranged from 1 to 1.4. Simultaneously, for $22.5 \%$ of living space, this index was less than one. Therefore, it is too risky to invest in such premises construction. This may be due to the high initial cost of such premises, as evidenced by the high average ratio of the initial planned cost to the developer's minimum allowable cost of housing. Thus, for most residential premises, which were examined for the investment feasibility, the investment risk is quite acceptable. Moreover for the housing, for which the investment risk is too high, it is necessary to reduce its price.

\section{Conclusions}

Risk planning in housing investment should be based on a preliminary assessment of the existing risk level. For this purpose, the indicators system of retrospective risk assessment in housing construction investment proposed in this paper can be used. This system contains indicators that allow you to assess the extent and economic consequences of each of the major risk events for investors, developers and intermediaries. It also allows you to establish the relationship between the risks inherent to their activities.

It is advisable for the investors, developers, and other participants of the housing construction investment process to use the developed in this work method of planning the housing construction investing risk level in their activities. This method involves constructing the probabilities distribution function of expected economic benefits from the residential real estate purchasing and construction. While using the developed method, it is possible to determine the reasonable share of risk premium in the price structure of the relevant construction products and calculate such numbers of the residential real estate value by considering the risk factors that are acceptable to investors and developers.

To quantify the riskiness level of housing construction investing, it is advisable to use the developed by the

Table 1

The planned indicators of the housing construction investing risk in the western region of Ukraine on a sample of residential premises, the construction of which was expected to begin in 2019

\begin{tabular}{|l|c|c|c|c|c|}
\hline \multicolumn{1}{|c|}{ Indexes } & \multicolumn{3}{c|}{ The indexes value for residential premises, for which the profitability index (5) is } \\
\cline { 2 - 6 } & $<1$ & $1-1.2$ & $1.2-1.4$ & $1.4-1.6$ & $>1.6$. \\
\hline $\begin{array}{l}\text { 1. The total living space fraction of the respective } \\
\text { group in the total area of all such premises, \% }\end{array}$ & 22.5 & 40.6 & 24.9 & 8.1 & 3.9 \\
\hline $\begin{array}{l}\text { 2. The average profitability index for the housing } \\
\text { purchase transaction, times }\end{array}$ & 0.91 & 1.08 & 1.28 & 1.41 & 0.17 \\
\hline $\begin{array}{l}\text { 3. The average ratio of the forecast value of the } \\
\text { coefficient of variation of economic benefits from } \\
\text { the housing purchase to the maximum possible } \\
\text { value of the coefficient of variation, unit share }\end{array}$ & 0.49 & 0.32 & 0.24 & 0.13 \\
$\begin{array}{l}\text { 4. The average ratio of the initial planned cost to } \\
\text { the minimum allowable housing construction cost } \\
\text { for the developer, times }\end{array}$ & 1.45 & 1.26 & 1.09 & 0.97 & 0.93 \\
\hline
\end{tabular}


authors the operation profitability index of the certain housing purchase. It is proposed to define this index as the ratio of a residential real estate object's estimated market value with taking into account the risk factor, to its initial estimated value. If the profitability index exceeds one, then the housing purchase should be considered appropriate. If the value of the profitability index is less than one, it is impractical to buy such housing. In the latter case, it is necessary to adjust the housing price in its reduction.

Further researches require, in particular, the development of a risk planning method in housing investing, depending on the chosen model of such investment.

\section{References:}

Abu Hassan, B. A. B., Ali, K., Onyeizu, E. N., \& Yusof, M. N. (2012). Evaluating risk management practices in construction company: Evidence from Oman. International Journal of Academic Research, vol. 4(2), pp. 32-37.

Akintoye, A. S. \& MacLeod, M. J. (1997). Risk analysis and management in construction. International Journal of Project Management, vol. 15(1), pp. 31-38.

Baloi, D., \& Price, A. D. (2003). Modelling global risk factors affecting construction cost performance. International Journal of Project Management, vol. 21(4), pp. 261-269.

Berk, C., \& Kartal, C. (2012). Determining major risk factors in construction projects from the view point of life cycle and stakeholder. International Journal of Business and Management Studies, vol. 4(2), pp. 11-20.

Chan, A. P. C., Scott, D., \& Chan, A. P. L. (2004). Factors affecting the success of a construction project. Journal of construction engineering and management, vol. 130(1), pp. 153-155.

Cho, S.-C., \& Eppinger, S. D. (2005). A simulation-based process model for managing complex design projects. IEEE Transaction on engineering management, vol. 52(3), pp. 316-328.

Doloi, H. (2009). Relational partnerships: The importance of communication, trust and confidence and joint risk management in achieving project success. Construction Management and Economics, vol. 27(11), pp. 1099-1109.

Flyvbjerg, B. (2006). From Nobel Prize to project management: Getting risks right. Project Management Journal, no. 37(3), pp. 5-15.

Ho, S. S., \& Pike, R. H. (1992). The use of risk analysis techniques in capital investment appraisal. Risk Analysis Assessment and Management, no. 104(2), pp. 71-94.

Jaafari, A. (2001). Management of risks, uncertainties and opportunities on projects: Time for a fundamental shift. International Journal of Project Management, vol. 19(2), pp. 89-101.

Lesinskyi, V., Yemelyanov, O., Zarytska, O., Symak, A., \& Koleshchuk, O. (2018). Substantiation of projects that account for risk in the resource-saving technological changes at enterprises. Eastern-European Journal of Enterprise Technologies, vol. 6, iss. 1, pp. 6-16.

Lian, H., \& Zhao, Y. (2017). Research on the financing risk management of the affordable housing construction system based on the dynamic optimisation theory. Revista de la Facultad de Ingenieria, no. 32(4), pp. $204-211$.

Renn, O., \& Benighaus, C. (2013). Perception of technological risk: insights from research and lessons for risk communication and management. Journal of Risk Research, 16, iss. 3-4, pp. 293-313.

Serra, C. E. M., \& Kunc, M. (2014). Benefits Realization Management and its influence on project success and on the execution of business strategies. International Journal of Project Management, vol. 33(1), pp. 53-66.

Shenhar, A. J., Dvir, D., Levy, O., \& Malth, A. C. (2001). Project success: a multidimensional strategic concept. Long range planning, vol. 34(6), pp. 699-725.

Yemelyanov, O., Symak, A., Petrushka, T., Lesyk, R., \& Lesyk, L. (2018). Evaluation of adaptability of Ukrainian economy to changes in prices for energy carriers and to energy market risks. Energies, vol. 11(12), p. 3529. DOI: https://dx.doi.org/10.3390/en11123529 